\title{
Introduction: The Pulse of the Arab Revolt
}

\author{
Mariz Tadros*
}

Abstract This article explores the dynamics of the rupture with the status quo that transformed the face of the Arab world. It examines the meanings of the pathways of social and political change in the light of some of the dominant paradigms that have informed policy and practice in the Arab world. In doing so, this article makes five key postulations that are relevant beyond the Arab context: the first is that we need new lens, new framings and new modes of engagement to capture the pulse of the street. The second postulation is that representing the uprisings as a 'Facebook revolution' is highly reductionist and risks promoting the replacement of one development fashion fad with another, without addressing the underlying power dynamics. This is especially so since the uprisings reached tipping point by virtue of a constellation of dynamics involving the youth, the masses and the army's military coup. Third, the time- and space-bound moral economy of Tahrir Square bears much explanatory power on why the act of revolting should not be confused with its outcome. The fourth contestation suggests that the concept of unruly politics may offer substantial analytical power in understanding the agency, the relationships and spaces through which people mobilised. The fifth argues that there is a need to rethink development policy in the light of a number of paradigm failures outlined below.

\section{Introduction}

Naming that moment of rupture with the status quo that transformed the face of the Arab world is no easy task. At the time of writing (October 2011), the political fates of Yemen and Syria were unsettled and in Egypt, the situation even more opaque: Mubarak had been toppled but the regime was intact. In Tunisia, there was a regime change that makes it easier to call it a 'revolution'. In Egypt, a variety of stakeholders have called the uprisings that began on 25 January and that led to the ousting of former President Mubarak, a revolution. Activists argue that since revolutions are not one-off events but processes that may take years to unfold, they insist that their struggle to topple the regime is sustained. At the time of writing, many Egyptian activists still spoke of the country being in a state of ongoing revolution to change the regime, namely, remove former Mubarak loyalists from the centres of power and governance; remove security officers with blood on their hands from within the Ministry of Interior and sever the ties with the old ways of engaging with political crisis through security, brutality and repression.

Guided by a very different agenda, the Supreme
Council of the Armed Forces (SCAF) and the transitional government in Egypt call it a 'revolution', as if it were a fait accompli.

Whether one names that 'rupture' across the Arab world an 'uprising', a 'revolt' or a 'revolution', what it definitely is not is an 'Arab Spring'. The Arab Spring was originally used by George Bush in 2005 to refer to the short-lived phase in which Arab leaders were opening political spaces for citizen activism, albeit in a controlled manner. This year, the Arab Spring was the most popular used phrase 'coined to describe the series of uprisings and social protests which have rocked the Arab world in the past year' (Wardrop 2011). Yet, in effect, the term in its use has come to confuse the act (the power of people's agency in topping corrupt rulers) with the outcome. The positivistic connotations of a 'Spring' betrays the reality on the ground in many countries, where the new political configurations of power seriously jeopardise the establishment of a political order based on the platforms upon which the people rose in the first place. In Egypt, Tunisia and Libya, the belligerence of some Islamist forces to

IDS Bulletin Volume 43 Number 1 January 2012 (c) 2012 The Author. IDS Bulletin @ 2012 Institute of Development Studies Published by Blackwell Publishing Ltd, 9600 Garsington Road, Oxford OX4 2DQ, UK and 350 Main Street, Malden, MA 02148, USA 
accepting full diversity and the human rights of all in the transition phase has made many local actors feel threatened about the possibility of the emergence of a democracy that is at once majoritarian and non-inclusive and intolerant towards deviance. In the case of Egypt, old red lines have been replaced with new red lines firmly enforced by SCAF in power; for example, Mubarak's central security brutality has been replaced with that of the military forces, ${ }^{1}$ while in other Arab countries, the dust has yet to settle. To term any country that witnesses an uprising as experiencing an Arab Spring is to assume that the actors who instigated the uprisings and their agendas as well as their relationship to the ruling powers are all one and the same - without any regard for the fact that due to their different agential dynamics and historical/political context, they are likely to produce very different political orders.

In view of the politically volatile and dynamic situation on the ground, this IDS Bulletin neither provides an historical account of political struggles that are very much ongoing, nor does it assess its impact or seek to predict its outcome. Rather, it is an attempt to analyse that moment when people revolted - when the tipping point was reached. The aim of this IDS Bulletin is to bring new empirical and conceptual insights on pathways of political and social change to an audience of development, area studies and democratisation academics, policy actors and practitioners who wish to interrogate the methodological and paradigmatic nuances of that rupture with the status quo. This IDS Bulletin engages with two specific but overlapping questions regarding that moment of rupture: how do we explain the way in which change unfolded at the wake of the uprisings? What can it tell us about the success or failure of development policies in relation to the January 25 th uprisings?

The first question raised challenges us to rethink our paradigms of how change happens in terms of, first, the actors and how they exercise their agency; second, the spaces in which power is subverted and confronted; and third, the processes through which collective action unfolds. The second question speaks to development policy very broadly, to include national public policy and international policies (and which often converge with democratisation promotion initiatives). Its focus on development policy in no way suggests that this is assumed to be the most salient or the only caveat that influences the course of historical events. However, it does speak to a relative gap in scholarship in examining development policy and praxis, in particular when compared with the growing body of literature that broaches international relations, social movements, history and technology/media vis-à-vis the 'Arab Spring'. Hence, the IDS Bulletin seeks to contribute to our understanding of why and how the uprisings began, and their implications for development paradigms, concepts and practices.

The focus of this IDS Bulletin is, on the whole, Egypt, although many of the articles have strong resonances with Tunisia, Yemen and other countries in the region and beyond. The choice of focus on Egypt was informed by its position in the Arab world and the ripple effect it has on other actors in the region, both in terms of governmental policy and civil society movements. Further, Egypt has been a laboratory for various micro- and macro-development fashion fads and policies for a long time. Its geostrategic significance has driven Western and Arab actors to invest large funds in the bid to influence its internal political configurations and public policies. Also, unlike Libya or Bahrain, where information on micro- and macro-internal dynamics is sparse, there is ample scholarship on Egypt. While a comparative approach examining the contextual nuances across countries is beneficial, due to the space limitations here, it was decided that in-depth insight into one country context may offer better defined policy messages than a more general one glossing over several country contexts.

This IDS Bulletin is distinctive in two respects: (1) its engagement with the Egyptian revolt by examining the development theory, policy and practice nexus, and (2) in the selection of contributors on the basis of their positionality. All contributors are Egyptians, who have one leg in activism and one leg in the policy-influencing arena $^{2}$ and whose perspectives are not commonly conveyed in mainstream academia, in some instances because of language barriers; in others because they have engaged with other forums and audiences, and in others because they have primarily focused on their activism. In Middle Eastern area study as well as in Development Studies there is clearly a bias in favour of the 
'experts' from the West. The events of the Arab world, argued Mona Abaza, an Egyptian sociologist, brought out the worst of the:

... unequal academic relationship between so-called 'local' and Western experts of the Middle East, between broadly speaking the North and the South (although this classification is clearly clichéd). Whereas the Western expert is the theoretician, the local academic is the informant or service provider. This situation, other than having orientalist overtones is a form of exploitation of the local academic community. In effect, 'many belonging to our scientific community have recently felt somehow 'misused' through being overwhelmed by Western touristrevolutionary academics in search of 'authentic' Tahrir revolutionaries, needing 'service providers' for research assistants, for translating, and newspaper summaries, for first hand testimonies, and time and again as providers of experts and young representatives for forthcoming abounding conferences on the Arab Spring in the West. 'Cherchez', the authentic revolutionary in each corner of the city, is the fashionable mood of these times. In theory, there is nothing wrong with providing services, had the relationship been equal, which was unfortunately never the case. (Abaza 2011)

This IDS Bulletin is in effect one modest step to reverse this trend, to give the floor to local voices, not only academics but also activists and practitioners. The contributors to this IDS Bulletin include: political activist Khalid Ali, founder of the Egyptian Center for Social and Economic Rights, who is deeply involved in both youth and workers' movements. Yusery Ezbawy has been working closely with many of the youth coalitions in Egypt. Youssef Wardany was an insider to the internal policymaking processes 'on the other side of the fence': he was the Editor in Chief of a youth newspaper run by the former ruling National Democratic Party (NDP) and he also served as a counsellor in the former Youth Minister's office. Sameh Fawzy is a renowned activist who championed the rights of Egypt's Coptic Christian minority and works extensively in Upper Egypt. Ayman Abd el Wahab, who leads the Civil Society Studies unit at the Ahram Center for Political and Strategic Studies, works extensively with large nationwide and small local non-governmental organisations (NGOs) across the country. Mohamed Hussein El Naggar is a human rights activist who holds much of the institutional history of the inner dynamics of the human rights movement in Egypt. Emad Siam is an activist with the Kifaya (Enough) movement and has worked closely with student bodies and movements across the country. Hania Sholkamy, professor at the American University in Cairo has led an action research project on conditional cash transfers for women in a slum area in Cairo, in collaboration with the Ministry of Social Solidarity. Yousry Mustapha has worked both as a human rights activist as well as a manager of donor-supported initiatives to promote human rights and women's rights on a national and regional level.

The voices are of politically engaged activists, and this is reflected in the narrative style and analytical framings. Some of the contributions do not follow the conventions of academic articles because of a conscious policy not to straitjacket the authors into a uniform academic style of presentation. This is not to suggest that the authors of this IDS Bulletin represent the wide diversity in class, background, religion or political orientation that characterises political society, nor does it negate that their visibility in Egypt is also informed by particular power hierarchies influencing who has access to the policy arena and on what terms. Nevertheless, they offer distinctive analyses because they are informed by particular positionalities and standpoints.

This article makes five principle postulations that are relevant beyond the Arab context: the first is that we need a new lens, new framings and new modes of engagement with capturing the pulse of the street. The second postulation is that representing the uprisings as a 'Facebook revolution' is highly reductionist. Third, the time- and space-bound moral economy of Tahrir Square bears much explanatory power on why the act of revolting should not be confused with its outcome. The fourth argument is that the concept of unruly politics may offer substantial analytical power in understanding the agency, the relationships and spaces through which people mobilised. The fifth contestation exposes the disconnect between democratisation/ development paradigms and the dynamics of unruly politics in authoritarian settings. 


\section{Taking the pulse of the street?}

No-one could predict the uprisings that led to the toppling of presidents who had been in power for two or three decades and more, partly because when the Tunisian and Egyptian youths first took to the street on 25 January, they initially called for political reform and only later did they raise the ceiling to toppling the regimes. The unpredictability of the uprisings was also associated with the great ambivalence vis-à-vis the position of the army. Moreover, we had long assumed that the peoples of Egypt and Tunisia (as in other authoritarian orders) had grown politically apathetic and, consequently, would not respond to calls to revolt. Even the secret political police in both contexts thought so. It is ironic that although the uprisings of Egypt were widely publicised - and planned for - the State Security Investigations apparatus (SSI) had severely underestimated the likely turnout of people in the protests and therefore, did not signal to other security sectors the need for further forces on the ground (Hassan and El Gahmy 2011).

The mass mobilisation of citizens that occurred surprised both the 'uprisers' and the wider policy of political and social analysts. Clearly, we had failed to get a sense of the pulse on the street prior to the uprisings. What is argued here is that international experts, local intellectuals, analysts and academics failed to capture the pulse because of the disciplinary silos through which we theorise and analyse what is happening on the ground, the limitations of the methodological precincts employed and the nature of power hierarchies in knowledge production and dissemination.

An example of the limitations of particular disciplinary approaches to the study of the street is in one strand of political science's deductive approach to the impact of political culture on people's agency. Political culture defined as the 'traditions of society, the spirit of its political institutions, the political ideals and the operating norms of the polity' (Dessouki 1971: 13). Several analyses had suggested that for a variety of reasons, both historical, institutional and cultural, Egyptians will not rise. Dessouki suggested that 'the average Egyptian regards public matters as none of his business', and explained that 'the Egyptian traditional passiveoriented political behaviour has to be seen in the light of three factors. Firstly, Egypt was governed for a long period of history by conquerors... Secondly, the long centuries of misrule and oppression are still alive in the memories and popular sayings of the people. Thirdly, there is a psychological readiness to accept de facto governments' (Dessouki 1971: 19, 20). Stacher (2001) argued that it is not so much the psychological lack of disposability to democracy, but that the configuration of authoritarian political arrangements have generated an apathetic political culture in Egypt. Similar arguments premised on political culture were made about other Arab countries. In a similar fashion, while Heydemann's (2007: 35) argument that Arab regimes kept re-inventing new strains of authoritarianism that could accommodate Western pressure to democratise stands, nonetheless the conclusion that the unmaking of authoritarianism in the Arab world, if it occurs at all 'will probably be less dramatic, more ambiguous and slower' has been contested.

The uprisings exposed not only the highly problematic assumptions informing the study of political culture as it applies to the Arab world but the skewed representation of reality, which is partly a consequence of the existence of disciplinary silos. The disconnect with the people's pulse suggests that alternative ways of engaging with complexity require crossdisciplinary approaches, and not just between politics and economics and anthropology but also involving media studies, literature and arts. Perhaps a combination of these may give a more nuanced understanding of the writings on the wall - in the literal and non-liberal sense.

More broadly, it is not only disciplinary silos that need to be challenged, but also methodological tools that have assumed an authoritative standing in giving us a sense of the pulse of the people on the ground. The unruly politics manifesto sees unruly politics 'as the dark matter of citizenship, governance and participation. We can't see it but it is what makes the whole system work'

(Shankland et al. 2011). The manifesto argued that 'We need to look beyond the visible spectrum of governance and recognise that because we have failed to "see like citizens" we have excluded unruly politics from our analysis and consequently failed to see change coming'. The power of surveys in being an accurate predictor of this, for example, needs to be revisited. A case in point is a 
much lauded nationwide survey published in Egypt in January 2010 (Survey of Young People in Egypt, SYPE), which gives us the following profile of the youth in Egypt:

Civic engagement of young people in Egypt is very weak in terms of participation in groups or organised activities and in voluntary work. Their social networks are limited to few friends and family, and these networks decline as young people age. However, young people are aware of Egypt's social problems and rated highly issues such as poverty reduction, economic growth, and health and education reform. Nonetheless, they do not invest time to learn more about the social and political issues from the available media. The political participation of young people is also weak; less than a fifth have ever voted, and only a few discuss politics among friends or are aware of their representatives in Parliament. The disengagement of young people could be due to their perceptions of diminishing values and trustworthiness in society and their direct experience of witnessing corruption. Their experience has produced in them a pessimistic view of the future. The only activity that the large majority of young people is engaged in and the one that appears to define their sense of identity is religion. Young people practice religion regularly in prayer and follow dress codes dictated by their faith, which defines their gender-related views and attitudes.

(UNFPA Egypt 2010: 145)

The survey's representation of the situation on the ground is in stark contrast with the scale and intensity of youth activism prior to the January 25 th revolution. So what accounts for this disconnect? On such highly contentious issues such as youth agency in a politically closed setting, there is always a possibility that what people say publicly (in a highly surveyed political space) does not reflect what they really think, let alone how they behave. Moreover, the reliance on a standard set of almost universal proxies used to measure civic engagement such as level of political participation and volunteering when applied to the context of Mubarak's Egypt can only produce highly misleading results. It is a well-known fact that the great majority of Egyptians did not believe in the integrity of the electoral system and therefore boycotted the elections. Moreover, as Abd el Wahab and Siam show in this IDS Bulletin, the opportunities for youth activism in conventional civil spaces such as volunteering in civil society organisations in Egypt were mostly blocked.

The uprisings have also exposed the need to engage with alternative sources of information on what is happening on the ground. For example, in recent years the Arab world has witnessed a proliferation of satellite channels which have managed to provide, to a certain extent, a freer space for political debates. In many ways, what the authorities, political activists and public figures said on the talk shows that were launched on these broadcasting stations, became far more politically insightful and revealing than the official statements that were published in the press. WikiLeaks have become a critical source of information of backstage politics that again, challenged the official narrative pronounced in formal spaces. Citizens' reactions to news stories published online and the nature of the debates that followed contribute to giving us a sense of the pulse on the street - at least in part. What such fora offered is the opportunity of participating in critical debates without the political correctness that stifles upfront engagement.

Moreover, Twitter, blogs, Facebook groups and other sites on the internet had become sites of subaltern engagements for educated groups whether they be based in Egypt, Tunisia, Yemen or even Saudi Arabia. These are highly dynamic spaces however, whose actors' ability to subvert, circumvent and resist their opponents is constantly being challenged. Ezbawy notes that one of the key strategic ways that the youth coalitions had sought to circumvent the powers of the SSI in Egypt was to convey the wrong information about where they were planning to congregate.

The challenge is to recognise that sites of information for grasping the pulse on the street are highly dynamic and will need to reconfigure in response to different kinds of encroachments. The CIA has picked up on these alternative spaces and has set up as part of its clandestine intelligence operations, an Open Source Center, which according to one report sometimes looks at 5 million tweets a day, and where analysts are constantly following television news channels, 
local radio stations and internet chat rooms. One report notes:

From Arabic to Mandarin, from an angry tweet to a thoughtful blog, the analysts gather the information, often in a native tongue. They cross-reference it with a local newspaper or a clandestinely intercepted phone conversation. From there, they build a picture sought by the highest levels at the White House. There might be a real-time peek, for example, at the mood of a region after the Navy SEAL raid that killed Osama bin Laden, or perhaps a prediction of which Mideast nation seems ripe for revolt. (Dozier 2011)

It is likely that dissidents will engage in unruly politics by continuously seeking to find alternative spaces on the margins that provide opportunities for contestation.

The above examples are not prescriptive for gathering insight into the pulse on the street, since they are intrinsically linked to the particularities of the context in which people engage. In Egypt and many Arab countries, one of the most influential sources of knowledge of the political dynamics at work is the soap operas produced for screening during Ramadan. They are highly political facets of all kinds of stakeholders' agendas. Equally so are anthropological approaches that rely on informal encounters with actors who are likely to be constantly in conversation with a wide array of people. In the context of Egypt (and probably many other countries), these would include barbers/hairdressers, grocers and taxi drivers. The credibility of the information gathered from such fluid sources may be questioned if they were the only source of data, however, when corroborated with other sources and when triangulation is deployed, they could cumulatively expose us to other layers of reality.

Yet, overcoming the impasse in taking the pulse on the street cannot be contested without addressing the epistemological question of the power hierarchies that inform representation, analysis and dissemination of knowledge. These are specifically to do with first, whose knowledge counts (in other words, who qualifies to be considered an expert) and second, our theorisation of what constitutes influential political action. Each will be briefly discussed below.
It is highly significant that while, for example, many local and international experts had dismissed the possibility of a people's revolt, other sources not conventionally considered as carrying political expertise, had forewarned the eruption of mass protests. Watching the first minutes of the Arabic film Chaos by Egyptian director, Khaled Youssef, where security clashed with youth, using tear-gas and batons, one would think that it is a documentary of the events that took place on 25 January, yet these images were enacted more than a year before the uprisings. The film tackled many of the issues that then became the catch cries in Tahrir Square - from the corruption and brutality of the security apparatus to the heavy encroachment of the ruling party on public life. Examples such as these indicate that our understanding of street politics requires that we inquire into the significance of a film like this and its resonance with the youth's consciencisation.

A related epistemological question over whose knowledge counts relates to the positionality of the 'expert' and how it affects the information gathering process. A WikiLeak cable of October 2008 described one member of the US diplomatic corps in Egypt's attempt to get a sense of the pulse on the street by visiting Cairo's many local coffee shops where (mostly) men meet up. He described the state of Egyptian politics as follows: 'The "passive" Egyptians smoking their water pipes gave no indication that anyone had plans to do anything but complain', the cable read. 'We picked up no hint of revolutionary fervor, no hushed whispers expressing admiration for an opposition figure or advocating any political change, or calling for a resort to violence', was his verdict. It is significant that nowhere in the cable did the US diplomat express the possibility that the fact that he is a foreigner, and an American, may have affected people's willingness to speak to him openly or to even engage with him in the first place.

Engaging people in conversation in coffee shops where the person already has the social capital to allow people to trust him/her may be an illuminative exercise in getting a sense on the street, but the positionality of the person will ultimately affect how people engage with $\mathrm{him} / \mathrm{her}$ - not least in a context where anyone and everyone was suspected of working as an informant for the SSI. 


\section{Power in unruly politics}

The uprisings that ruptured the status quo challenge us to rethink the mechanisms, the agendas and the actors we associate with social and political activism. As Ali and Dahi argue in this IDS Bulletin, thousands of protests were regularly taking place in the past decade in Egypt. The protests became so frequent, suggested Ali in a personal conversation, that he could not keep track of them anymore, nor did the press bother to report all of them. Yet these protests, he argued, were important precursors to the revolution because they served as the political incubators for politicised action for many and provided them with the organisational skills needed to act collectively. While these protests were going on, many leading opposition public figures and intellectuals were lamenting why Egyptians do not rise. ${ }^{3}$

We missed these episodes of public dissent because these forms of collective action did not fit our checklist of what constitutes the right way to challenge the status quo by the right citizenry. When workers, labourers, farmers and Copts organised protests, these were often shunned as too narrow in their representation and demands, especially since they were not calling for the overthrow of the regime. In other words, these were not protests that counted towards chipping at the status quo. The same dismissive attitude has informed many of the analyses of the continued protests by the same groups in Egypt after the revolution that underestimate their potential impact for catalysing broader processes of mass political contestation.

There was an equally derisive response from many of the local intelligentsia towards the tactics deployed to show public dissidence as lacking in a radical edge or a sufficiently forceful assault on the ruling authorities to be of any effect. Yet in many cases, dissidents were aware that clashes with the security would lead to their incarceration and repression, so they found other ways of being disruptive using what McAdam $e t$ al. (2001) would typically call mechanisms of contentious politics. One of the most successful mechanisms was the 'Stay at Home' campaign launched by the April 6th youth movement in 2008, via Facebook and text messages calling upon people not to go to work. The strategy subverted the security apparatus threats against workers who dare to strike or citizens who protest in solidarity. Groups of citizens informed the politicians by making noise with pots and pans that they were hungry. The April 6th youth movement raised straw broomsticks in front of the shrine of the Prophet's daughter, at the Sayeda Zeinab district, to signal that the country is in need of a clean-up.

What is significant is the form of the agency citizen groups, which did not derive from the conventional agents of change; they were not civil society organisations, not social movements and not political parties - in other words, they were not the usual suspects of the development and democratisation policy domains. They could not be neatly compartmentalised into types of civil society organisations because in most cases, they did not have an organisational structure in the first place. At the same time, these actors and forms of contestation were not only on the fringes of what the public authorities and donors consider orderly behaviour, as when the uprisings began in Egypt, Tunisia and Yemen, they were neither instigated by civil society organisations nor political parties nor religio-political forces such as the Islamists. It is in this sense that such actors' engagement in unruly politics is so critically important. Unruly politics here is defined as the marginal space through which citizens engage politically outside the conventional realms of state and civil society. Irrespective of whether unruly politics achieves its desired outcomes, its dynamics will mean that the status quo is being fundamentally shaken at its very fabric.

If we take the continuous stream of protests from diverse groups as a reflection of the state of anger on the Egyptian street, this can well mean that we cannot exclude the possibility of another major revolt - either in the form of a counterrevolution or a major confrontation with the remaining remnants of the regime, at the head of which is the army.

The significance of unruly politics manifests itself when we examine the political landscape of activism in Egypt prior to the uprisings. Abd el Wahab's article shows that civil society in Egypt by and large no longer served as the arena for contestation, except on the fringes (professional syndicates and workers' independent groups). His analysis suggests that civil society organisations had become too orderly, too politically contained 
for engagement in contentious politics, so much so that when youth wanted to become politically active, they sought other spaces and other mechanisms that are neither institutionalised nor under the auspices of particular organisational umbrellas. Mohamed Hussein El Naggar's article on human rights organisations suggests that although they played an indirect role in raising awareness of human rights violations in Egypt, their elitist nature organisationally and in relation to their approaches and interventions meant that their spaces were rather exclusionary.

Emad Siam notes that even the Islamist organisations affiliated to political Islamic forces, which have been widely publicised to provide the alternative platforms for charity outreach and development praxis witnessed a waning of their influence in later years. Siam suggests that against a backdrop of security restrictions and the ideological inflexibility of the movement leaders, young people and the middle-class who wished to express their religiosity in community outreach established alternative organisations. Siam argues that there is a strong possibility that these newer organisations that do not seem to be directly linked to the Islamist political movements may outdo the older models affiliated to the Muslim Brotherhood and the Salafi movement.

What is striking is the extent to which many civil society organisations working in development and in human rights had come to be completely disconnected from the wider polity, and which became manifest in their absence of a constituency. Their meetings, workshops and conferences held in four and five-star hotels had become one of their principle activities tackling issues that had little resonance in the wider society. The outcome was a poor turnout, so much so that some organisations went as far as to pay participants (LE20-30 per head) to attend events. The situation was particularly dire for the 'boutiques': organisations that were formed by persons with no relation to civil society for the purpose of capitalising on the surge of foreign funds, such as that made available under the USsponsored Middle East Partnership Initiative (MEPI) (Tadros 2009). Many mainstream civil society organisations had become completely depoliticised as an outcome of security encroachment and conformity to foreign funding requirements. Groups of independent professionals and young people's movements were formed, attracting new supporters outside these conventional organisational structures and engaging in unruly politics in lieu of the more diluted advocacy and campaigning strategies that had become so popular in the formal spaces.

In short, while contentious politics directs our attention to the processes and dynamics of activism, unruly politics alerts us to the spaces often hidden and informal - through which agency expresses itself. It also provides us with an opportunity to analyse more deeply the relations of contention, which in the case of many Arab countries were not only characterising hostility towards the state but towards the conventional civil and civic actors and their positioning in the existing power hierarchies.

\section{The constellation and convergence of tipping point(s)}

Technology may have facilitated the processes of mobilisation by certain actors and at certain points, but it cannot account for the mobilisation of millions to revolt, nor the ousting of Mubarak. In contrast to some of the narratives of the Egyptian uprising that seem to suggest that the Facebook youth were responsible for the rise of the revolt and the demise of Mubarak, what is suggested here is that there were a number of critical tipping points involved in the uprisings that began in Egypt, Yemen and Tunisia. In the Egyptian context, it is possible to identify a number of tipping points: the tipping point that made it possible for people to overcome the fear barrier and go out in their millions and the tipping point that led to the ousting of Mubarak. The narrative of the events unfolding for the period prior to the ousting of President Mubarak was diluted of some of the unpredictability, ambiguity and complexity, which are critically important for our understandings of the unfolding power dynamics.

The ousting of President Mubarak after the 18 days of mass protest was the outcome of a constellation of three actors: the youth who organised, the people who went out in masses and the armed forces who opted for a military coup. Each will now be discussed separately.

\subsection{The youth}

It is important to note that the youth who planned the January 25th demonstrations were 
not initially planning for a millioniyya (one million person protest) that would eventually lead to the ousting of Mubarak. The youth who planned for the event did not only rely on media technology, although that played an important role, but they also spread the word in several neighbourhoods by distributing pamphlets and passing on catchy slogans through word of mouth. The youth, who were largely educated and of the petit bourgeoisie and middle-class, were planning for a protest event on 25 January, at which they would present their calls for reform. However, when they were subjected to extreme police brutality on that day, this immediately had a knee-jerk reaction in propelling more people to join. The youth organisers managed to do what political parties had more or less failed to do during the Mubarak years: form a strong collective coalition (rather than broad-based social movement) across ideological, class and religious divides. There was no leadership but there was a high level of synchronisation and coordination during those 18 days.

\subsection{The people}

The people responded in their masses. Why? Some of the slogans touched them in the light of their own sense of oppression. The slogans included: 'Our people, join us, freedom is for you and us'. Some came out because their sons, daughters, loved ones, friends and relatives were there in Tahrir Square and the government had cut the mobile phone networks, thus making people feel anxious about the safety of their loved ones. Some came out because they were told that 'if you go and protest, the government will give you your lost rights (right to an apartment, to a raise, and so on)' or because they identified with these youth in their sense of being fed up - and because from the moment the military went down to the streets and did not shoot, they realised that there was a possibility that they may not get razed to the ground. But also Al Jazeera brought into people's homes images of unarmed youth being attacked with tear gas, being brutally beaten and dragged on the floor and this emboldened many not to let it pass.

It was, in the words of Yusery Ezbawy, a snowballing process (this IDS Bulletin) - that had much to do with unplanned reactions as careful strategising on the part of the 'uprisers'. Protestors stayed because they knew that if they were to go back, they may end up being seized by the security apparatus and spend the rest of their lives in an unknown prison (if not a worse fate). Some stayed in follow-up to the 'Battle of the Camel', ${ }^{4}$ which convinced them of the government's lack of sincerity in abandoning the use of brute force.

The power of the people lay in their number and their persistence. As General Adly Fayed, former deputy to the Minister of Interior, the second man in charge of political and security matters after the Minister, argued that the reason for the fall of the security services when faced with the protests was that 'it worked on the $25 \mathrm{th}, 26 \mathrm{th}$, 27 th and 28 th January $2011 \ldots$ the full number of central security forces does not exceed 120,000' (El Badry et al. 2011). As he acknowledged in the same interview, the protestors outnumbered the security officers by far.

\subsection{The military}

The stance of the military in relation to the government's leadership (represented by the President) represents one of the most decisive factors in explaining why the revolution was successful in Egypt and Tunisia, and not so in Syria or in the early stages in Yemen and Libya. The power struggles within the military and their relationship to the USA is an aspect of the uprisings that at this stage we know very little about.

In Tunisia, General Rashid Ammar, the chief of the staff of the armed forces, is said to have refused to order troops to fire with live ammunition against the demonstrators. Days after he refused, Ben Ali fled to Saudi Arabia. However, the army was growing hostile toward the president long before Ammar's refusal to shoot, and may have been implicated in a plot brewed against the Ben Ali regime in the spring of 2002. (The army already had its misgivings against Ben Ali, not least because of his handling of the plane crash that killed Ammar's predecessor, General Abdelaziz Skik, as well as 13 other senior officers.) Investigation results were never publicly announced (Kallander 2011).

In Egypt, a number of options are possible regarding the military's role. According to a WikiLeak message relayed by Margaret Skoby, the then US Ambassador to Cairo, in 2008: 'Since 2003, the regime has tried to strengthen the economic elite close to Gamal [son of former 
President Mubarak] at the expense of the military in an effort to weaken potential military opposition to Gamal's path to the presidency. Other analysts believe the regime is trying to co-opt the military through patronage into accepting Gamal and that despite tensions between the military and business, their relationship remains cooperative' (WikiLeaks 2011). There are a number of scenarios: the first is that the army initially sided with Mubarak until it realised that street power is strong and likely to be sustained; the second is that for a long time they had been waiting for the right political moment, and this was the perfect opportunity for a non-bloody military coup. As the STRATFOR security report suggested, 'What has been going on is a quiet coup by the generals designed to save the regime while easing out an old friend'. ${ }^{5}$ Evidence seems to suggest that the army only began to side with the people after 28 January, when there was a turnout of a million people. It is possibly at this point that the army decided that if it were to protect its interests (given that they were part of the regime) it had too much to lose if it took a stance against the people (see e.g. Baz 2011).

Further ambiguity regards the role of the USA in influencing the course of the events, more so in Tunisia and Egypt than in Yemen and Libya. Beyond the official White House discourse, it is interesting that on 25 January when the uprisings began in Egypt, a military delegation was on an official visit to Washington DC. As for Tunisia, the TuniLeaks ${ }^{6}$ can be read in a way to suggest that well before January 2011, the USA was seeking alternative candidates to Ben Ali. ${ }^{7}$

\section{A time- and space-bound moral economy}

While many analyses recognise that the revolution was hijacked by the army and the Islamist forces, dimensions of what happened in Tahrir Square before the ousting of Mubarak were somehow assumed to be reflected in the power configurations that unfolded afterwards. Here it is argued that an understanding of the nature of the moral economy of Tahrir Square has some explanatory power of why this was not so. It was a moral economy that was both timeand space-bound. The sense of moral indignation at the political and economic injustices succinctly captured in the call for 'bread, freedom and human dignity' inspired both youths and ordinary citizens to join the ranks of the protestors. What unified people across gender, religion, class, age and profession was a common goal: to rid the country of Mubarak. The slogans that were used in Tahrir Square served to reinforce the emergence of a new narrative or script that would help unify the people, such as 'Muslim Christian one hand' which was commonly shouted and 'Not the [Muslim] Brothers, not the parties, our revolution is a youth revolution' which was deployed to override the deep rifts in political society. In Tahrir Square, a new moral economy emerged that was guided by a common Egyptian project: the ousting of the president.

This moral economy was civil both in the sense of being civilised (its non-violent, peaceful nature in the face of police brutality and infiltrators and thugs) and in the sense of not assuming a politicised religious character. It also manifested itself through the images of volunteers walking with plastic bags removing any rubbish from within the Tahrir Square on a regular basis. It was also one where gender norms of engagement were reconfigured: women, veiled and unveiled, moved freely and in late hours of the day, without being subjected to any harassment. In cases where a Sala $i^{8}$ expressed his indignation at a woman's attire, someone would tell him, 'This is not the time for this now, let us keep focused on our aim' and this would be enough to make him retreat. When people shouted religious slogans, many more shouted back 'Civil! Civil!'.

However, this moral economy was space-bound. Tahrir Square did not represent the whole of the nation. Moreover, the peaceful nature of the protests was not observed everywhere: in Ismailiya, there were some deadly confrontations; in Alexandria, police officers were murdered and the Islamist flavour of the protest was conspicuous and widely pervasive; and in Cairo, there were assaults on public buildings that symbolised government oppression.

The moral economy of Tahrir Square was also time-bound. The agreement that was made between the Islamists and the other political factions and the youth that no slogans, flags, party lines would be raised except those patriotic ones was immediately abandoned by the Islamists after the ousting of Mubarak as they prepared for the battle of the ballot boxes. The tolerance shown towards women's full agency 
was abandoned in favour of one that reinforced gender stereotypes and hierarchies in the name of undoing the First Lady's Women's

Empowerment Agenda (even if it was not that empowering at all). ${ }^{9}$ The backlash against those who did not prescribe to the religious normative framework of the Sunnis began with attacks on the shrines of the Sufis, attacks on the Baha'is and a stream of attacks on the country's largest non-Muslim minority, the Copts, manifested in the burning and closure of several churches, the expropriation of property and the exclusion of Christians from many villages in Upper Egypt.

What the above suggests is that actors (in particular youth) and forms of agency (in particular the use of technology) need to be examined in an embedded manner (i.e. as it functions within a set of relations in a particular context) - taking into account where they converged with other agendas and interest groups to elicit and where they were marginal to the political processes. Mobilising via Facebook, for example, offered the youth coalition members very limited opportunities for forging a mass political constituency following the ousting of Mubarak - in particular in the light of a very different configuration of political powers because the majority of Egyptians do not communicate via the internet, and there are other competing spaces through which ideas and agendas are mobilised (such as the mosque). Yet, keeping the memory of the moral economy of Tahrir Square alive is important for many youth activists to withstand attempts by political forces to claim ownership of the revolution.

\section{The policy disconnects}

The uprisings in Egypt and Tunisia, and perhaps to a lesser extent, Yemen, have exposed a number of disconnects between how particular paradigms were officially deemed functional in comparison with the situation on the ground. One of the most controversial is the disconnect between the publicised state of the economy and the people's predicament on the ground. While the International Monetary Fund (IMF) warned that the Tunisian economy needs to address unemployment and may be affected by the crisis in its European partners, it however established that: 'Over the past two decades, the North African nation has undertaken wide-ranging structural reforms aimed at enhancing its business environment and improving the competitiveness of its economy. These reforms, accompanied by prudent macroeconomic management, have reduced the Tunisian economy's vulnerability to shocks - including the global financial crisis - and provided more options for the authorities to respond to them' (Toujas-Bernate and Bhattacharya 2010).

Yet, Nadia Marzouki (2011) deciphers a direct link between the failure of the Tunisian government to provide employment opportunities and the uprising. The Tunisian events, although surprising to almost everyone, were not a random outburst of frustration. Rather, they represented the logical consequence of an unsustainable formula for fake political and economic stability, the very formula that many Western policymakers have lauded as the 'Tunisian miracle'.

The IMF's appraisal of the state of Egypt's economy in 2010 was also positive, noting that: 'Egypt's economy has been resilient to the crisis. Financial contagion was contained by limited direct exposure to structured products and low levels of financial integration with world financial markets. Sustained and wide-ranging reforms since 2004 had reduced fiscal, monetary, and external vulnerabilities, and improved the investment climate. These bolstered the economy's durability and provided breathing space for appropriate policy responses'. ${ }^{10} \mathrm{In}$ Yemen, interviews conducted by the author with families in Sanaa in April 2010 revealed the extent to which a war in the north, inflation and diminishing economic opportunities were taking their toll on their families, who were having to cut down severely on food and reduce their children's attendance at school because the conditions had become so dire. It was the poor soldiers' families that were also hit, not just those who work in the private and informal sectors.

However, as Dahi argues (this IDS Bulletin), the Arab states may have won the approval of the West in deepening economic liberalisation but in the process politically alienated themselves and lost their social base.

The social base of many of these Arab regimes was initially founded on what Dahi terms 'an authoritarian populist social contract', established at the time of independence, and which provided some social and economic 
benefits in return for political acquiescence. This base, he argues, was eroding with the abandonment of the provision of a modicum of social and economic services (education, health and employment opportunities), but became acute in the last few years and which was met with increasing political dissidence.

One core group that had not benefited from the previous social contract and was alienated politically, economically and socially, was the youth. Youssef Wardany meticulously documents the various dimensions of Mubarak's youth policy to show that despite the existence of a youth ministry, and a bundle of 'youth policies', none of them were working on the ground. Wardany identifies a number of policy failures, the most important of which include: the lack of a political will to prioritise the youth and the absence of any synchronisation between various government authorities to implement a functional policy. As the demarcations between the government and the ruling national democratic party became increasingly blurred, the youth portfolio came under the tutelage of Gamal Mubarak while the women and children portfolio was held by the First Lady (Wardany 2011). Gamal Mubarak counted on the leadership of the NDP to create a constituency from the youth in his favour. The plan, as Wardany shows, backfired. The absence of coordination of a holistic policy on youth is an important message for development policymakers in populations with a large cohort of young people. Age will need to be an important identifier as with gender, class and other qualifiers.

Moreover, the uprisings also represented a revolt against corruption in Egypt, Yemen and Tunisia. While there is a consensus among most international policymakers of the poor quality of governance in these countries, the extent to which the normative World Bank agenda of good governance was able to speak to local realities is at stake. Fawzy (this IDS Bulletin) argues that in order to fully grasp the extent to which corruption had affected Egyptian citizens, it is important not only to look at the lack of vertical and horizontal accountability, but the extent to which it became almost impossible not to be implicated or embedded in relations of corruption for daily survival. In her article (this IDS Bulletin), Tadros shows that in effect, it was the SSI that was running the country and not the ministries and formal institutional structures mandated with governance roles. By playing a backstage governance role, the SSI was able to keep in place the image of a government responsive to international calls for political reform, while in effect making the status quo immune from any change.

There is a need for a paradigm shift that takes into account the relational dimensions of governance. In other words, while an institutional approach is needed to reform government ministries and departments, this in and of itself will be insufficient to enhance citizens' engagements. Ultimately, the absence of a political will on the part of the donors to engage with the politically contentious nature of governance showed the limitations of technical fix it approaches that focus exclusively on introducing new institutional schemes (such as e-governance projects) without changing the underlying power dynamics of engagement.

Hania Sholkamy (this IDS Bulletin) similarly exposes how the attempted implantation of an apolitical gender and development policy disconnected from the wider political context failed to capture the imagination of women and men with visions of a socially and politically inclusive society. Ironically, the moment of the uprisings opened the floodgates of activism, achieving in those instances an extraordinarily high level of women's political participation that years of development programming and microprojects had failed to achieve. Yet, in postMubarak Egypt, the gender agenda could go either way. The politicisation of women's agency means that it is not being dealt with in the projectivised and compartmentalised manner characteristic of many development programmes supported during Mubarak's reign. On the other hand, the rise of the Islamists' political power threatens to reinforce patriarchal gender division of roles, in particular through the charity outreach programmes that engage with women as religious subjects with needs rather than entitlement mentality.

None of these policy disconnects on their own the failure of the economic model, the failure of governance, the failure of civil society organisations - or any other public policy in and of themselves, explain why the uprisings started. However, their constellation, together with the right political catalysts and the right political moment, forged the enabling environment for the mobilisation of the masses. 


\section{In search of paradigmatic shifts}

The Egyptian and Tunisian revolts have revealed a number of disconnects whose policy relevance goes beyond the Arab region. The first such disconnect is associated with our ability to capture the pulse on the street or at least elements of it, and the challenge this presents on both epistemological and methodological grounds. Epistemologically, the limitations of disciplinary silos have been exposed. What accounts for expertise needs to be revisited. The assumptions that have informed the experts' sense of what is happening on the ground have been contested (in particular those associated with political culture), as well as the theoretical frameworks that have informed understandings of which forms of people's agency are politically significant and which are not. Moreover, we also need to rethink the extent to which the use of some measurement tools are appropriate for the phenomenon we wish to capture in a particular context in taking the pulse on the street. What is argued here is not that we should abandon conventional methods of data collection (qualitative and quantitative methods) but that we need to be open to alternative sources as well, in particular those that provide the spaces for citizen engagement electronically and those that emanate from the study of popular culture.

Revisiting the economic paradigm may also lead to the reconsideration of what constitutes economic success. If the revolts witnessed in Egypt, Tunisia and Yemen are to be considered as revolts against neoliberal orders as they are on political repression, then it is likely that international economic policymakers and institutions will be forced to reconsider recipes for economic development, sources of data on the situation on the ground, and impact assessment. In Egypt and Tunisia, civil movements have been formed to advocate for the cancellation of debts ${ }^{11}$ and there are official steps being taken to return the country's frozen assets from Swiss Banks. ${ }^{12}$ Clearly, as calls for economic justice assume transnational dimensions, the long-term economic costs of tolerating dictatorial leaders who show a high level of cooperation in implementing neoliberal policies will need to be re-thought. In Tunisia, WikiLeaks suggest that this had already begun to happen in some quarters of US government. 'If the cables are accurate, they suggest that the State Department is beginning, however dimly, to understand the political consequences of these economic policies, many of which, while applied in Tunisia are "made in America"... and referred to as "The Washington Consensus"". ${ }^{13}$ In post-revolution Egypt, workers' movements and political activists are not only attacking the mismanagement of economic resources by the government, but the very neoliberal paradigm itself by calling into question the economic premises for privatisation and a minimalist approach to welfare provision.

There is also a need to rethink the civil society paradigm in relation to social and political action. Clearly, civil society organisations, the long-time donor darlings of development and democratisation policymakers, were not at the forefront of the instigation or mobilisation of the people's uprisings whether in Egypt, Tunisia or Yemen. This offers an important lesson in recognising the multiplicity of actors and forms of agency that exist on the ground and in finding locally sensitive and appropriate ways of identifying collective initiatives on a long-term basis and not only individual boutique-like organisations (i.e. supporting coalitions not only particular organisations).

Regrettably, as Yousry Mustapha's article (this IDS Bulletin) on donor engagements shows, foreign policy interests continue to supersede the promotion of policies that serve to create an enabling environment for progressive social and political actors. A paradigmatic shift that engages with the local landscape differently has not happened and it is badly required: the need to move beyond 'needs assessment', undertaken with the usual suspects when developing longterm strategic interventions - which must be informed by more nuanced context-sensitive power analysis. Very much tied to this is the need to avoid replacing one development fashion fad with another. Funding 'social media' has taken centre stage, replacing earlier development fashion fads like grassroots development and conventional forms of advocacy. This shift from one fashion fad to the other may serve to create new enclaves of social media elites who also run the risk in the long run of becoming disconnected because they are lacking a constituency. This is not to suggest that social media initiatives should not be supported, only that a more embedded approach is needed - one that draws on the hard lessons of the need to go beyond assumed pathways of social and political change. 
Notes

* The author would like to thank Chris Toensing and John Gaventa for the helpful feedback to an earlier draft of this article. All disqualifiers apply.

1 See for example, a documentary video released on 11 November on YouTube by the Egyptian civilian-led 'No to Military Trials Campaign', www.youtube.com/watch?v=00tONEwc3E\&feature $=$ player_embedded

2 With the exception of Omar Dahi, who is of Syrian origin and an assistant Professor of Economics at Hampshire College, USA.

3 See for example, the articles of renowned writer Ibrahim Issa and novelist Alaa El Aswany.

4 Mounted charge by government loyalists on Tahrir Square, in February which resulted in the injury of approximately 1,000 peaceful protestors.

5 STRATFOR, 29 January 2011, 'Mubarak and the Egyptian Military', unauthored.

6 TuniLeaks, http://tunileaks.org/ (WikiLeaks on Tunisia).

7 See 'Deconstructing Tunileaks', 20 December 2010, http://nawaat.org/portail/2010/12/20/ deconstructing-tunileaks-an-interview-withprofessor-rob-prince-university-of-denver/ (accessed 10 November 2011).

8 Salafis are a movement comprised of many different groups who believe in the return to al salaf al saleh, which refers to the righteous past as lived by the companions of the Prophet in the first three centuries of Islamic society.

\section{References}

Abaza, M. (2011) 'Academic Tourists Sightseeing the Arab Spring', Al-Ahram online English version, 26 September, http://english.ahram.org.eg/ /NewsContentP / 4/22373/Opinion/Academic-touristssightseeing-the-Arab-Spring.aspx (accessed 26 September 2011)

Baz, Muhammad (2011) 'Ijtima'at Al-Mushir wal Ra'is Ayyam al Thawra', Al Fajr, 2 October, http://m.elfagr.org/dailyPortal_NewsDetails.as px?nwsId $=8043 \&$ secid $=10$ (accessed 17 October $)$

Dessouki, A. (1971) 'The Mass Political Culture of Egypt: A Case Study of the Persistence of Cultural Traits', The Muslim World 61.1: 13-20

Dozier, K. (2011) 'CIA Tracks Revolt by Tweet, Facebook', Associated Press, 4 November, www.google.com/hostednews/ap/article/ALeq M5jGuH2XxQaLndlUL9ZyCHrblyaUKA?doc
9 The First Lady's efforts to introduce a number of legal reforms in family legislation (and against which there has been a backlash in post-Mubarak Egypt).

10 IMF, Arab Republic of Egypt, Article IV 'Consultation Mission, Concluding Statement', Cairo, 16 February 2010, www.imf.org/external/np/ms/2010/021610.htm (accessed 8 November 2011).

11 For the Egyptian campaign, 29 October 2011, 'Egyptians Plan Popular Campaign to Drop Egypt's Debts', Al-Ahram, http://english.ahram.org.eg/NewsContent/3/ 12/25435/Business/Economy/Egyptians-planpopular-campaign-to-dropEgypt\%E2\%80\%99s-de.aspx; and for the Tunisian campaign, Hussein, M., 'Tunisian Debt Relief Campaign Supports Egyptian Equivalent, Says Head', 2 November 2011 , http://english.ahram.org.eg/ NewsContent/3/12/25799/Business/Economy/ Tunisian-debt-relief-campaign-supportsEgyptian-eq.aspx (both accessed 15 November 2011).

12 Egypt Press News, Youm 7 (English edition), 29 August 2011, http://english.youm7.com/ News.asp? NewsID = 344192 (accessed 15 November 2011).

13 'Deconstructing Tunileaks, Part Two, Economic Consequences', Nawaat (blog), 22 December 2010, http://nawaat.org/portail/ 2010/12/22/deconstructing-tunileaks-part-twoeconomic-consequences/ (accessed 10 November 2011).

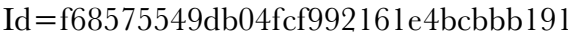
(accessed 5 November 2011)

El-Badry, Y.; Shalaby, A. and El-Dessouky, F. (2011) 'Head of the General Security: Any Order comes from the Minister of Interior and Al Adly is Responsible Politically and Security-wise', Al Masry al Youm, 22 April: 15 Hassan, M. and El Gahmy, H. (2011) 'The Testimonies of the Officers turn the Hanging Rope around the Necks of the Ministry of Interior Leaders', Al Shorouk, 20 April: 7

Heydemann, S. (2007) Upgrading Authoritarianism in the Arab World, Analysis Paper 13, Washington DC: Saban Center for Middle East Policy at the Brookings Institute

Kallander, Amy (2011) 'Tunisia's Post-Ben Ali Challenge', Middle East Report Online, 26 January, www.merip.org/mero/mero012611 (accessed 15 November 2011) 
Marzouki, Nadia (2011) 'Tunisia's Wall has Fallen', Middle East Research and Information Project, www.merip.org/mero/mero011911 (accessed 10 October 2011)

McAdam, D.; Tarrow, S. and Tilly, C. (2001) The Dynamics of Contention, New York: Cambridge University Press

Shankland, A.; Tadros, M.; Hossain, N.; ScottVillers, P. and Khanna, A. (2011) Unruly Politics Manifesto, 19 May, PowerPoint presentation made at seminar at IDS, Brighton

Stacher, Joshua (2001) 'A Democracy with Fangs and Claws and its Effect on Egyptian Political Culture', Arab Studies Quarterly 23.3: 83-99

Tadros, M. (2009) Advocacy in the Age of Authoritarianism: A Case Study from Egypt, IDS Working Paper 338, Brighton: IDS

Toujas-Bernate, Joël and Bhattacharya, Rina (2010) 'Tunisia Weathers Crisis Well but Unemployment Persists', IMF Survey Magazine, www.imf.org/external/pubs/ft/survey/so/2010/ car091010a.htm (accessed 8 November 2011)

UNFPA Egypt (2010) Survey of Young People in Egypt: Final Report, 14 December

Wardany, Y. (2011) 'The Pulse on the Arab Revolt', workshop convened by IDS at the Flamenco Hotel, Cairo, 14 September

Wardrop, M. (2011) “"Occupy” is the Most Commonly Used Word in English Language Media, Claims Study', The Telegraph, 10 November, www.telegraph.co.uk/news/ newstopics/howaboutthat/8881273/Occupy-ismost-commonly-used-word-in-Englishlanguage-media-claims-study.html (accessed 14 November 2011)

WikiLeaks (2011) Academics see the Military in Decline, but Retaining Strong Influence, released 30 August, http://wikileaks.org/cable/2008/09/ 08CAIRO2091.html\# (accessed 1 November 2011) 